\title{
Research on the Archives Social Service
}

\author{
Lu jimin \\ Yunnan University of Finance and Economics \\ (532065727@qq.com)
}

\begin{abstract}
With the continuous development of archives social service, the archives social service has played a more and more important role in the social and economic construction. And it is an inevitable trend of social development for archives social service. Based on the substantial resources of archives, archives social service is a system which established on archives information resources through various channels and forms to develop and utilize archives resources.
\end{abstract}

Keywords: Archives; Society; Service

\section{The necessity of the archives social service}

The archives are essentially public cultural institutions, with a purpose to provide satisfied information service for the society. In the new period of social development and social change, developing archival social service is not only the needs of their own development, but also the inevitable requirement of archives basic function for strengthening the construction of archives public service ability.

Firstly, strengthening the archives social service is an urgent requirement to construct harmonious society, implement the scientific concept of development and speed up the pace of economic construction. The most direct result of strengthening the archives social service is to effectively expand the archives information resources "radiant surface", which broadens the communication between the archives and the public, and makes the former "rib". The public can use archives to collect information resources, what is more simple and easier to guarantee every citizen's knowing right, also could be cold "human rights". The archives social service has played a positive role of understanding history, reality and future, maintaining and safeguarding the rights and interests of all citizens in the democratic aspects. It is also conductive for the realization of social fairness and justice and the promoting development of economy and social stability.

Secondly, it is an urgently need for strengthening the archives social service to adapt to the development of social culture and regional culture inheritance. Archives connect the social practice of human activity and the rational thinking activity, and continuously provide fresh nutrients for human social and cultural life, and also make human activity to be a dynamic cycle process of constant development. The base of scientific research, the archives, is also the center of various aspects using historical documents, which plays a positive role for social and cultural heritage and development.

Thirdly, it is an urgent need for the archives social service to the transformation of archives work in the new period. According to the nature of the document, the function and the requirement of social development of modern archives work, the archives, as the subjects of archives in the new social development, must strengthen the construction of archives social service ability, comprehensive transformation and innovation, to maintain the sustainable development of the archives social service work. 


\section{The status social service}

In our country, the archive socialization degree is relatively low and mainly showed below:

\subsection{Collection aspect}

Although some archives in our country have begun collect some family's archives closely to citizens, the domination of archives' work is to collect national business archives. Thus, the personal archives are less and has not formed a climate within a certain scope.

\subsection{Management aspect}

Domestic archives in our country are formulated by fixed personnel to manage archives, but fewer volunteers, temporary workers can take part in the archives work.

\subsection{Service aspect}

Although the government in China put forward the slogan of "active service, convenient for user", in the overall, it is the red tape, simple conditions and a few utilization way, which makes the number of the archive difficult to rise. In the construction of website, although domestic archives website has been established, it is less available to access to information for users. Most archives can not reach this level as our country is a developing country. Nowadays with the progress of society, we should draw lessons from foreign archives in all kinds of advanced social practice to promote the archives in our country.

\section{The existing problems and reasons in the archives social service}

\subsection{Consciousness of the archives social service}

At present, the consciousness of the archives social service is generally weak. The "consciousness" is for archives users. That is to say, as the archives are relatively independent and closed for a long time, the social awareness of archives work is less, and the work of propaganda is not enough. These problems contribute to a result that the archives resources can not prochoice real effect in the construction of social development.

\subsection{Weakness of the archives social service}

As the foundation of the archives social service work is not yet perfect, such as insufficient abundance of archive resource, low level of informatization, low degree of development and utilization, we should strengthen the foundation of the archives social service work further.

\subsection{Weakness of strengthening the archives social service}

Due to the restriction of management system, law, technology and so on, the archive social service is still not satisfied, as the public archives is not rich, the content of channel is less, and the way is relatively single.

\subsection{A single manner of archives social service}

The methods of archive social service are mainly site service, mail service and other traditional ways. There are fewer requests about network, telephone, fax and other modern communication ways, and it is a very small proportion in archives social service. Therefore, the archives social service is still confined to "you come and I take", and satisfied with archive borrowing, copy and other low level of back-end services.

\section{Some suggestions on strengthening archives social service ability}

In view of many difficulties the above archives in the development in our country, it is necessary to analyze the specific issues with measures on local conditions of the policy. Started from the above -mentioned problems, this author puts forward the following 
suggestions to strengthen archives social service ability.

\subsection{To strengthen the construction of archives} base

First of all, we must strengthen infrastructure construction in archives department as the infrastructure construction in archives is the first condition in the construction of archive function. Because of the present situation of inefficiently use about archives library, we should rebuild archives system to expand the collection capacity and improve the conditions of archives preservation. What's more, we should update the ideas on archives construction, and design the site selection with advanced ideas, in order to build the suitable and open atmosphere, provide convenience service for citizens, and make the basic function of the archives properly. In terms of internal equipment, we could eliminate a number of tools behind the times, and configure a number of high-tech equipments to meet the demand of era, according the actual ability of every archive.

\subsection{To enhance the consciousness of the archive social service}

\subsubsection{Setting up the concept of archival social} service

Archive information service is the way of manifesting the file value, the driving force for the development of the archives, and also basic factors of archives work. In the age of information, archives collection, sorting, identification are the basis of archives work, and the using of archives is the ultimate goal. It can also be said that the service is the basic nature of archives work, and it is the only choice of survival and development and eternal topic to improve the quality of service. The archives should break boundaries of walls, establish the open idea, and regard the library information resources as the common wealth. And it should carry out the work of "the user first" to take the purpose of "all for the sake of users, for users of all" into reality.

Archive utilization is the central task of the archives work through which the value of archives can be achieved. As archives are an important part of archives in our country, to speed up the development of archive information resources, to improve social service function, are very important to satisfy the public's growing demand of the use of archives. Meanwhile, it is the objective requirement of the archives development to expand archives openness and effectiveness of public service for the society under the new historical conditions.

\subsubsection{Carrying out active service}

Active service is a trend that attaches great importance to the study and grasp the social demand, and it will provide product, which the society requires. Archive service work focus es on the development of social economy and culture construction process. It searches and finds the break point to meet the needs of society combining site to satisfy the multi-level and diversified demand of citizens and then to show the role of archives.

It is an important reflection of transforming the model of service to master archives users' demands. Only in this way, can be targeted to carry out archives service, and realize the transition from the passive service to active service. There are three aspects below to master records about the user's demand characteristics: Firstly, the hierarchy of user's need. Because of the difference of archives between users, the demands are also different. Some users may need only once time archives information, but others may need twice or three times archives information. Secondly, the diversity of user's requirements. The diversity of demand for archives 
information is showed as the need from users, such as different occupations, hobbies, qualities and so on. Thirdly, the indelibility of user's requirements. Archives can guide the regulation of user's demand.For example, the archives publicity can influence the change of user requirements and make some potential desire a conscious behavior. When the policy and environment changed, something that is not available before, may become convenient to use.

\subsubsection{Paying attention to the archives publicity}

The socialization of archives social participation is an important symbol to measure the archives. It should not only provide quality services, but also extend service to society, to serve each domain, for archives social service. To realize the socialization of archives, propaganda work is an indispensable way, the lifeblood of the survival and development. The social significance of archives is to sustain the link between human society space-time unity and integrity of important medium. As a result, the concept of archives information socialization should include two aspects: one is to set up and strengthen social consciousness of the archivist; And the other is whether the society can do or not. As the social consciousness of archives and the society's archives consciousness are two interdependent aspects, we must strengthen the social consciousness of archives industry firstly to raise awareness of the society's archives consciousness, and also intensify the publicity of archives and make society more familiar with archives, especially letting more researchers to have access to the archives for academic research.

\subsection{To innovate archives social service}

As one important part of the archives business, archival service work is an eternal subject of archives work. The ultimate goal of arranging all kinds of archives is to use and serve economic development, social harmony and social progress. The department of archive must work hard in the optimization services, and combine with the actual work, in order to find a proper breakthrough point for the archives work, whose purpose is to provide the Omnidirectional, multi-level and high levels of archives social service. At present, the methods of traditional archives service mainly include reading, copying, lending, archives certificates, etc. These ways for archives are the most basic ways, but they only rely on the condition that traditional ways of services are not enough. In the age of information, we should also try to use modern means, such as computer, network, to perfect archives social service, which makes the service mode of archives work more flexible, broader and more significant.

\subsubsection{To construct network platform of information service}

Restricted by the archives secrecy, although it is not possible for archives department to open archives resources for the society, it can be through the website (Internet) of archives messages, established in order to provide related services. Setting up information network platform and archives online service, sharing resources of archive collection, are the important ways to realize the archives service socialization. Archives repositories shall actively adopt modern computer technology and communication means to construct a rich and full of personalized website. We should use archives information of "open-window" services, "file searching on the net" services, regularly publishing files directory services and full text information services, to provide public information services in a maximize way of realization the sharing of archives information between the archives and society. In the process of website construction, We should consider 
more for visitors and to be truly people-oriented, in order to meet the demand of the public.

\subsubsection{To develop modern archive consulting services}

Through the establishment of archives website, we can introduce information about library archives and related services, but we must notice that no matter how advanced the technology, advanced equipment they are, verbal communication between person and person can not be replaced. For this purpose, the archives department should make great efforts to carry out modern archives consulting service. Modern archives consulting service is an higher intelligence intensive service about information, skill and knowledge, which are the output form of the service. Archives' reserves are rich in knowledge, technology and information, and they own a large number of professional and technical personnel to make archives consulting service has a huge advantage. Archives consulting service work is the inevitable requirement of archives information socialization. Now more and more enterprises realize the importance of archives information, and eager to get professional business guidance from the administrative department to improve the archives management level of the unit. Archives can play their own advantages, just like some of the archives work in the enterprises and institutions to provide advisory services.

\subsubsection{To set up a joint collaboration of information services}

To realize socialization service, We must change the habit of doing things by closing doors, expand the function of archives service, and collaborate with other institutions of information services. With the aid of computer, network and other modern technology and equipments, through the collaboration mechanism between the information service units, it is common to solve problems facing the information needs to the archives

\subsubsection{To set up archives project services}

In order to make archives service really accepted by the public, and play its social value, archivists should determine the direction and service content through social investigation, to understand the social demand of archives. The archivists select useful file information from the documents, and on a regular basis, actively provide service to meet the social demands for archives information. These effective ways to carry out archives social services.

\subsubsection{To set up the electronic reading room}

Established on the basis of computer, database and network of modern electrical archives information service mode, electronic reading-room sets up to realize efficient use of services. Electronic reading room is a digital archive sites for people to read, provides the digital archives information, and can also be applied to the electronic reading room of the multimedia computer technology and the remote communication technology, connecting the internet, in order to realize the online search information at home and abroad. Users can get archives information through email, data exchange, database and so on, they even can make use of e-commerce to subscribe to the required copy of documents and archives research products.

Establishing electronic reading room can build a directory central firstly, and then scan Internet files directory and volumes directory into a web page using the hyperlink function of web page creation software and digital archives to connect them one by one. When Arthur refer to digital archives, according to the years, directory number provided by the digital archive directory in electronic reading room, they 
can surf the Internet, and look up to the required documents.

\section{References}

[1]Zhang lingual. The Social Service Function of Citizens' Right to Information and Archives of Expanding[J].Archives Science Bulletin.2007.1.

[2]Deng Yu. Social Studying Multimedia College Archives and Archives Resources[J]. Archives and Construction.2007.8.

[3]Dong Bao. Analysis of Archives Service Socialization Problems[J]. Lantai World.2005.4.

[4]Zhang Li. Try to Talk About the Archives Information Service Socialization[J].2005.2.

[5]Xu Wei. The Archives Social Service[J]. Lan ai World.2009.5 